\title{
"Conmigo, el sueño americano no se cumplió» \\ Desigualdades de raza y clase en las trayectorias biográficas de hijos de migrantes zapotecos en Estados Unidos
}

\section{«In my Case, the American Dream was not Attained» Race and Class Inequalities in the Biographical Trajectories of Zapotec Migrant Children in the United States}

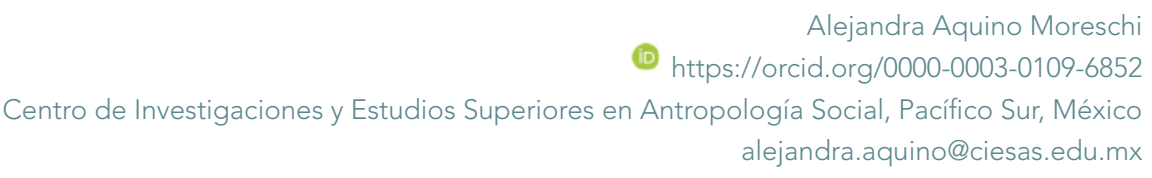

\section{Resumen:}

Este artículo explora, a partir de un enfoque biográfico, de qué forma los hijos de migrantes zapotecos nacidos en Estados Unidos experimentan las desigualdades estructurales que se derivan de las jerarquías de género, clase y, particularmente, «raza». Argumento que estos jóvenes deben responder simultáneamente, y en profunda condición de desventaja, a dos proyectos normativos que buscan regular su incorporación a la sociedad: la transición a la vida adulta y la asimilación a la sociedad de acogida de sus padres. A partir de tres trayectorias biográficas se muestran las grandes barreras raciales que enfrentan los jóvenes al tratar de cumplir con estos proyectos normativos en un contexto en el que todo está estructurado de manera que su inclusión social sea improbable o se realice en términos muy precarios.

Palabras clave: Migraciones, asimilación, racismo estructural, juventudes.

\section{Abstract:}

This paper uses a biographical approach to explore how US-born children of Zapotec migrants experience the structural inequalities derived from gender, class, and particularly «race». It contends that these Zapotec youths, who are at great disadvantage must simultaneously respond to two normative projects regulating their social inclusion: transition into adulthood and assimilation into the society receiving their parents. Using three biographical trajectories, this paper exposes the significant racial barriers these young people face upon attempting to comply with these normative projects in a context that is so structured that social inclusion is unlikely or is extremely precarious.

Keywords: Migrations, assimilation, structural racism, youth. 
a migración mexicana a Estados Unidos es una de las más antiguas y numerosas en la historia de ese país, en el cual hoy habitan 36 millones de personas de origen mexicano (Flores, 2017) quienes a lo largo del siglo XX han sido la principal fuente de mano de obra para la economía estadounidense (Portes, 2006; Massey, 2008). Sin embargo, como muestra la investigación de Telles y Ortiz (2008; 2011:506), los mexicoamericanos «después de cuatro generaciones se han trasladado principalmente a la clase obrera y a la clase media baja», mientras un número muy grande de ellos se encuentra en una situación de pobreza; estas desigualdades se reflejan también en sus logros educativos, los cuales, para la cuarta y quinta generación, siguen siendo inferiores a los de los estadounidenses de origen europeo (Telles y Ortiz, 2011:506).

Según las teorías de la asimilación, para la tercera generación los descendientes de migrantes tendrían que estar completamente integrados a la vida nacional (Gordon, 1964), lo que no solo significa el aprendizaje de la lengua y cierto grado de «aculturación», sino también haber alcanzado los niveles de bienestar del grupo dominante (Portes y Zhou, 1993). Como señala Ortiz (2017:3), «los mexicoamericanos si bien participan ampliamente en la sociedad: hablan inglés, votan y consumen muchos aspectos de la cultura popular», además de pagar impuestos y trabajar, la realidad es que su situación socioeconómica y educativa se ha mantenido estancada durante varias generaciones.

En el discurso público, e incluso académico, las desventajas socioeconómicas y educativas de los mexicoamericanos se han explicado a partir de diferentes prejuicios y estereotipos en clave culturalista, los cuales se han tomado como «prueba» para demostrar que este grupo tiene muchas dificultades y resistencias para asimilarse a la cultura angloamericana protestante. Por ejemplo, el politólogo Samuel Huntington (2004a), cuyo trabajo ha influido fuertemente en cierta clase política estadounidense, ha sostenido, apoyándose en otros autores, que los mexicanos le otorgan «baja prioridad a la educación» y se resignan a vivir en la pobreza porque sus valores católicos y su cultura los llevan a considerar que esa es una manera de "ganarse el cielo». Estas explicaciones -sin sustento científico-, que responden más a prejuicios y estereotipos racistas, se encuentran ampliamente extendidas en los discursos públicos y en el sentido común de una parte de la población. En contraste, el papel que juega la racialización y el racismo estructural en la vida de los mexicoamericanos se ha mantenido invisible (Telles y Ortiz, 2011). 
Como señala Bonilla-Silva (1997:476), en la actualidad:

Las prácticas raciales que reproducen la desigualdad racial en Estados Unidos, 1) son cada vez más encubiertas, 2) están arraigadas en las operaciones normales de las instituciones, 3) evitan la terminología racial directa y 4) son invisibles para la mayoría de los blancos.

Sin embargo, numerosas investigaciones sí han mostrado que históricamente los mexicoamericanos han sido racializados (Montejano, 1987; Ngai, 2004; De Genova, 2006; Massey, 2008; Telles y Ortiz, 2008; Ortiz y Telles, 2012), es decir, que fueron construidos como un "grupo racial», percibido como «no blanco», ubicado en lo más bajo de una estructura social (Ortiz, 2017) fundada y arraigada en un sistema de supremacía blanca (Valdez y Golash-Boza, 2017). Entonces, aunque en el discurso público y en los censos los mexicoamericanos sean considerados una «minoría étnica», su experiencia cotidiana corresponde a la de un grupo racializado, que durante varias generaciones ha enfrentado múltiples desventajas y severas barreras raciales que estructuran sus oportunidades en el día a día (Ortiz y Telles, 2012). ${ }^{1}$

Este artículo busca abonar a la comprensión de cómo los hijos de migrantes mexicanos experimentan dichas barreras raciales en un momento particular de su curso de vida: la juventud. En específico, propongo analizar desde un enfoque biográfico (Bertaux, 1999; 2005) cómo los hijos de migrantes indígenas de origen mexicano establecidos en la ciudad de Los Ángeles, California, experimentan las desigualdades estructurales que se derivan de las jerarquías de género, clase y «raza», ${ }^{2}$ y de qué forma estas impactan sus trayectorias biográficas y los orientan hacia distintas formas de inclusión o exclusión social. Se trata de jóvenes que nacieron en Estados Unidos o que llegaron cuando eran muy pequeños a ese país, y que en la literatura sobre migración son denominados como la «segunda generación» y la "generación 1.5», respectivamente (Portes y Rumbaut, 2005).

Este texto parte de la hipótesis de que estos jóvenes deben responder, en condiciones de profunda desventaja, a dos proyectos normativos que buscan gestionar la inclusión social: por un lado, la sociedad adulta y sus instituciones esperan que transiten exitosamente a la adultez, lo que implicaría que «se formen y adquieran todos los valores y habilidades para una vida adulta productiva

1 El que sean considerados como un "grupo étnico» en el discurso público y en los censos, permite invisibilizar su tratamiento como «grupo racial» y todo el racismo que conlleva.

2 Entrecomillo la categoría de «raza» para enfatizar que carece de sustento biológico. 
y bien integrada socialmente» (Alpizar y Bernal, 2003:5). Por otro, al ser hijos de migrantes, la sociedad espera que se asimilen lo más pronto posible a un país en el que, si bien nacieron o crecieron, no son bienvenidos y no se les brindan las mismas oportunidades que a otros jóvenes.

El artículo es resultado de una investigación etnográfica multisituada, tanto en México como en Estados Unidos, que duró poco más de una década (2005-2018) con migrantes zapotecos de la localidad de San Isidro, ${ }^{3}$ una comunidad indígena trasnacional que ha construido su vida entre Oaxaca y Los Ángeles, California. En particular se deriva de un subproyecto de investigación cuyo propósito fue explorar cómo se reproduce una situación estructural de desigualdad entre la segunda generación de migrantes zapotecos.

En la medida en que esta investigación se interesa fundamentalmente por las formas en que los hijos de migrantes experimentan las desigualdades estructurales, la elaboración de relatos de vida desde un enfoque biográfico será una herramienta central. Los relatos de vida son una forma privilegiada para acercarnos al universo de significación de los actores (Bertaux, 2005), pero además nos permiten comprender, desde la experiencia del sujeto, fenómenos de tipo socio estructural (Bertaux, 1999).

Las entrevistas que sustentan las tres trayectorias biográficas que presento en el artículo fueron realizadas en 2005, 2006 y 2013 en Los Ángeles, California, y forman parte de un conjunto más amplio de entrevistas a otros jóvenes de origen zapoteco, así como a sus padres. Gracias a mis vínculos familiares con algunas personas de la comunidad de San Isidro, tuve un acceso privilegiado a los hogares y a las cotidianidades de mis interlocutores durante mi trabajo de campo y pude entrevistarlos en distintas ocasiones.

\section{Transición a la adultez y asimilación: proyectos normativos para la gestión de la inclusión social}

En este artículo parto de la hipótesis de que los hijos de migrantes deben hacer frente, de manera simultánea, a dos proyectos normativos que buscan regular su incorporación a la sociedad en una etapa temprana de su curso de vida: la transición a la vida adulta y la asimilación a la sociedad de acogida de sus padres. Ambos proyectos buscan normar estas transiciones y para ello han

\footnotetext{
${ }^{3}$ El nombre del pueblo y el de todas las personas que aparecen en el texto fue modificado para salvaguardar su identidad.
} 
establecido criterios específicos que definen la forma en que deben realizarse, así como los modelos ideales que les sirven de referencia para evaluar las diferentes trayectorias.

En Estados Unidos existe una larga tradición en el estudio de los jóvenes desde un enfoque sociodemográfico, el cual analiza la juventud como un periodo de «transición a la adultez», marcado por una serie de eventos vitales que modifican el rol social de los individuos: completar la educación formal, entrar al mercado laboral, casarse, formar un hogar independiente y el nacimiento del primer hijo (Mora y Oliveira, 2009:270). Desde esta perspectiva, la transición a la vida adulta se ve como un periodo del «curso de vida», en el que los individuos son moldeados por una serie de instituciones sociales como la escuela, la familia y el mercado de trabajo, las cuales buscan asegurar su integración social (Mora y Oliveira, 2009:270).

En ese país existe también una importante tradición en los estudios en torno a cómo los migrantes y sus descendientes se incorporan a la sociedad. El enfoque predominante ha sido la teoría de la asimilación en sus distintas vertientes. Esta se ha convertido, al mismo tiempo, en una ideología política y en un proyecto normativo muy presente en los discursos públicos y en los imaginarios colectivos de la sociedad y de los propios migrantes.

Desde la vertiente clásica, la asimilación se entiende como el proceso lento y gradual, pero inevitable, de movilidad ascendente que lleva a los migrantes y a sus descendientes a incorporarse al "grupo dominante», es decir, a la clase media anglosajona (Gordon, 1964). La velocidad en que se da la asimilación variará en función de cada minoría, pero normalmente debe haberse realizado para la segunda o tercera generación. Para evaluar el grado de asimilación se han priorizado indicadores como el aprendizaje del inglés y la incorporación de los valores y la cultura anglosajones, pero también los logros educativos, el ascenso social y el acceso a los mismos niveles de bienestar que los estadounidenses (Gordon, 1964; Alba y Nee, 1997; Portes y Rumbaut, 2005; Telles y Ortiz, 2008).

Desde la teoría de la asimilación se clasifica a los inmigrantes y a sus descendientes en función de su origen nacional y analíticamente se les trata como «minorías étnicas»; el foco de su análisis está puesto en cómo estas minorías son incluidas a la vida estadounidense (Valdez y Golash-Boza, 2017:2). La migración europea de principios del siglo XX ha servido de referente y de modelo para evaluar a todos los migrantes que llegaron después, independientemente de 
su origen nacional y del contexto histórico y sociopolítico en el que se realice su migración (Alba y Nee, 1997). El problema, como señala Ortiz (2017:6), es que en estas comparaciones no se ha considerado -o se ha minimizado- el hecho de que «ser blanco» ha sido un privilegio en este proceso de integración, mientras que no serlo, en cambio, constituye una enorme desventaja (cf. Yankelevich, 2015).

En ambos casos, estos enfoques normativos han recibido diversas críticas que los han llevado a flexibilizar sus respectivos modelos y a incorporar nuevos factores de análisis que reflejen de mejor manera lo que sucede en el contexto actual. Por ejemplo, en el caso de los estudios sobre juventud, algunos autores abordan la importancia que tienen habilidades como la autonomía y la responsabilidad en el proceso de hacerse adultos (Mora y Oliveira, 2009). Por su parte, las nuevas teorías de la asimilación han mostrado el papel que juegan las políticas migratorias dirigidas hacia las minorías, así como la discriminación y la segmentación de los mercados laborales (Alba y Nee, 2003; Portes, Fernández-Kelly y Haller, 2006).

Además, se muestra cómo en un contexto de desregulación de instituciones, como la familia y los mercados de trabajo, cada vez es más difícil una transición en los términos que señalan los modelos hegemónicos, y se ha constatado que las trayectorias de los jóvenes y de los migrantes avanzan en distintos sentidos y que pueden desembocar en trayectorias de exclusión social. Por ejemplo, Saravi (2006; 2009) ha mostrado que las trayectorias de los jóvenes ya no son lineales ni estables, sino que están marcadas por idas y vueltas inciertas, con entradas y salidas sin permanencia, tanto en el mercado laboral como en el hogar materno.

En lo que respecta a las teorías de la asimilación, Portes y Zhou (1993) han señalado que existen por lo menos tres caminos diferentes de asimilación: 1) la «asimilación ascendente» con aculturación, la cual sigue la vía de ascenso descrita por la teoría clásica de la asimilación; 2) la «asimilación ascendente» con «aculturación selectiva», implica que las personas logran un ascenso social pero sin necesidad de perder su cultura y su lengua, en esta trayectoria se afirma la propia etnicidad y se refuerza la solidaridad con la comunidad co-étnica; y 3) la «asimilación descendente» que se da hacia los sectores más empobrecidos de la sociedad (Portes y Zhou, 1993:82).

El análisis simultáneo de la transición a la adultez y de la asimilación-enfocados a la vez como procesos y como proyectos normativos- me permitirá una mejor comprensión de la experiencia de los hijos de migrantes zapotecos en Estados Unidos, así como de los principales retos y dificultades estructurales que han 
enfrentado en sus luchas cotidianas por mejorar su vida. Poner al centro de mi análisis estos procesos no significa que pretenda «evaluar» o «valorar» el «éxito» o el "grado» de la asimilación o integración social de los hijos de migrantes zapotecos, más bien, quiero mostrar las dificultades que enfrentan para hacerse un lugar en la sociedad y responder a las altas expectativas sociales en un contexto que les es profundamente desfavorable.

\section{Las hermanas López: experiencia escolar}

Rosa y Laura López son hijas de la señora Gloria y del señor Pedro, migrantes zapotecos radicados en Los Ángeles, California, desde hace varias décadas. Don Pedro emigró a esa ciudad a mediados de la década de 1970 cuando todavía era soltero; unos años más tarde regresó a San Isidro para casarse con doña Gloria y, en enero de 1980, la nueva pareja se estableció en la zona centro sur de Los Ángeles. En ese momento ninguno de los dos contaba con papeles, pero en el marco de la Amnistía de 1986 pudieron regularizar su situación. ${ }^{4}$ Como casi todos los migrantes de San Isidro, don Pedro ha trabajado en la cocina de varios restaurantes y doña Gloria en la limpieza de casas y el cuidado de ancianos. En 1982 nació su primogénito, tres años más tarde llegó Rosa y en 1992 nació Laura, la última hija. Al momento de la última entrevista, Rosa tenía 28 años y era madre de cuatro hijos. Laura tenía 21 años y acababa de ingresar a la universidad.

Para ambas la escolarización ha sido una experiencia de segregación por «raza» y clase, ya que, como ellas señalan, sus escuelas además de ser las «más low» de todo Los Ángeles, están destinadas de manera exclusiva a la población latina y afroamericana. Cuentan que en toda su escolarización no tuvieron un solo compañero «blanco», ni de clase alta. La segregación escolar se relaciona fuertemente con la segregación habitacional, pues asisten a las escuelas que les corresponden por su lugar de residencia. En estas escuelas, ellas han enfrentado en cada etapa las mismas situaciones:

Nuestras escuelas siempre tenían muchos alumnos y no nos daban tanto la educación que deberíamos tener en nuestro nivel. Por eso muchos de nosotros cuando pasamos a la secundaria ya estábamos muy atrasados. Y en la secundaria lo mismo,

${ }^{4}$ En 1986 se aprobó la Ley de Reforma y Control de Inmigración (IRCA) que permitió la legalización de 2.7 millones de migrantes indocumentados. 
nuevamente las escuelas estaban muy pobladas (...) Ya luego me fui al high school y la prepa a la que yo fui es la prepa más low... la que tiene el peor nivel, una de las peores escuelas de Los Ángeles (...) Las maestras que tuve, muchas fueron muy malas, muchos eran maestros que tenían muchos años ahí; ellos nunca dedicaban cierto tiempo para cada estudiante. Además de que mi escuela era la "más baja", o sea, era una escuela mala en reputación, todavía querían sacar maestros y querían quitarnos muchas clases que nos ayudaban (entrevista, 2013).

A lo largo de toda su escolaridad, Laura solo recuerda a un maestro que sí se preocupaba por sus alumnos, los alentaba y pensaba que sí tenían capacidad para llegar a la universidad. La mayoría de sus profesores más bien reforzaba la mirada negativa sobre estas escuelas y su alumnado; los maestros no creían en el potencial de los niños y estaban convencidos de que no podrían avanzar en sus estudios. Se ha demostrado que las proyecciones de los profesores tienen un gran impacto en el éxito o fracaso escolar de los alumnos (Suárez-Orozco y Suárez-Orozco, 2001). Esta situación ha provocado escepticismo en Laura y Rosa sobre lo que pueden esperar de la institución escolar:

Ahí solo te dan lo mínimo y solamente si tú quieres sobresalir, tú lo vas a hacer. Tú tienes que querer salir adelante y tú poner tu propio empeño para ser alguien, porque ellos no van a estar detrás de ti, ni te educan ni les interesas, ellos nada más están ahí para recoger un cheque, no para que tú llegues a la universidad (entrevista, 2013).

A lo largo de su escolarización, las hermanas López no solo sufrieron racismo estructural que condicionó su trayectoria escolar y su relación con la escuela, sino que lo experimentaron en sus interacciones cotidianas, en este caso derivado del lugar que ocupan en la estructura étnico-racial del país de origen, en la que aquellas personas clasificadas como «indígenas» han sido racializadas. Rosa y Laura explican que, si bien en la escuela todos son «latinos y supuestamente son la misma 'raza'», ellas experimentaron la desigualdad en el trato por tener un color de piel «más oscuro» y una «apariencia indígena». Como explica Laura:

Solamente porque me veo como que soy... pues ellos te clasifican, tal vez no es un racismo pero sí es una discriminación porque ellos se basan en lo que ellos piensan y, porque tú te ves indígena, ellos piensan que tú no sabes inglés, que tú no sabes nada, piensan que tú eres más burra... (entrevista, 2013). 


\section{Embarazo temprano y deserción escolar}

La trayectoria escolar de Rosa se vio interrumpida por un embarazo a la edad de 16 años y, con ello, sintió que también su juventud terminó abruptamente. Esta situación sorprendió a su familia, porque, desde pequeña, Rosa se destacó por sus buenas calificaciones, además, como señalan sus familiares, «ella era una niña muy lista y muy despierta, desde chiquita hablaba muy bien inglés, y era quien llamaba al número de emergencia cuando había un problema». Su embarazo la enfrentó a la desaprobación moral de la familia y de la comunidad de paisanos. La presión social no solo fue para ella sino también para su madre, a quien criticaron por «trabajar tanto» y «descuidar a sus hijos». Doña Gloria dice:

yo he hablado con mis hijos y les digo: "discúlpenme si yo no he podido darles atención, pero yo siempre he pensado en que ustedes tuvieran un techo, y si yo me quedara en casa dándoles amor, atendiéndoles... pues voy andar pidiendo dinero prestado, voy a andar dándole la misma comida todos los días, la misma ropa, o andar en apartamentos rentados". No, yo dije: "yo a mis hijos les voy a dar estudio, casa, comida, de lo que yo no tuve". Por eso yo trabajé mucho. Siempre les he dado lo máximo que he podido. Si yo me hubiera quedado en la casa así como él hace, ¿de dónde vamos a sacar? [...] Yo imagino mi vida como si fuera una gallina que nomás tiene un ala, porque siempre él ha fallado, yo hice todo el ahorro para comprar esta casa y no he dejado decaer un solo pago (...) Entonces he hecho mis paguitos y he criado a mis hijos y les digo a mis hijos: "perdóname si no pude darles atención, pero yo he querido darles lo mejor" (entrevista, 2013).

El embarazo a una edad temprana es un hito determinante en la trayectoria de las mujeres, ya que con frecuencia obliga al abandono escolar y hace que se refuercen situaciones previas de pobreza. Cuando Rosa habla de su embarazo y de su deserción escolar explica los hechos como un «error personal» relacionado con sus «malas decisiones»:

yo iba bien en la escuela, simplemente fallé al tomar decisiones equivocadas, pero la escuela no era difícil para mí. A mí todo me gustaba, me iba bien, pero me empecé a juntar con la gente equivocada y por muchas cosas que me pasaron en mi vida tomé muchas decisiones que me llevaron a mi propia destrucción, de cierta manera (entrevista, 2013). 
Sin embargo, los embarazos adolescentes y la deserción escolar no pueden verse simplemente como "errores» de las jovencitas o de sus padres, ya que son resultado de una estructura social que, al excluir y racializar a ciertos grupos, sienta las condiciones para que estas situaciones se reproduzcan. La encuesta realizada por Portes (2006:81) muestra que entre los mexicoamericanos se concentra un número elevado de embarazos adolescentes; encabeza la lista con $41 \%$ de jóvenes que tuvieron hijos en los primeros años de su vida adulta, en contraste con $3 \%$ de los cubanos. En la investigación encontró también que los mexicoamericanos tienen el «peor perfil» en rendimiento académico, ya que «dos de cada cinco (un 38\%) no consiguen ir más allá del bachillerato y poseen la más baja media de años de escolarización de la muestra» (Portes, 2006:81).

Desde las teorías de la asimilación esta situación se ha explicado centralmente como resultado del «bajo estatus socioeconómico y nivel educativo de los padres», del «tipo de familia» y del «tipo de incorporación inicial al país» (Portes y Hao, 2005; Alba y Nee, 1997). Sin embargo, una investigación más reciente con cuatro generaciones de mexicoamericanos demuestra que la falta de avance en la educación de este grupo refleja su tratamiento como un grupo racial estigmatizado, en lugar de ser simplemente producto de un bajo capital humano de los padres inmigrantes o de las otras causas sugeridas en la literatura sobre asimilación (Ortiz y Telles, 2012:1). Para Telles y Ortiz (2011:507-508), existe «una serie de prácticas institucionales e interpersonales de discriminación y racismo que limitan el logro educativo de los mexicoamericanos», entre estas destacan la disparidad en la calidad de las escuelas a las que asisten, la baja expectativa de los maestros con respecto a su rendimiento, los estereotipos negativos sobre sus capacidades y sus posibilidades futuras, entre otras cuestiones que afectan sus oportunidades de éxito escolar.

Cuando el embarazo ya fue muy notorio, Rosa tuvo que abandonar la escuela, puesto que la institución está hecha para que no existan posibilidades de quedarse; las jóvenes embarazadas suelen recibir mucha presión por parte de compañeros, profesores y padres de familia, quienes las ven como un «mal ejemplo» para otras chicas. El embarazo adolescente -tanto desde el proyecto de asimilación como del de la transición a la adultez- es visto como una «patología» que orientará la trayectoria de las jóvenes hacia la exclusión. Este enfoque moral de un problema social y estructural reproduce los estereotipos racistas con los que se retrata a la comunidad mexicoamericana. Incluso desde la academia, de 
nuevo, Samuel Huntington (2004b) ha sostenido que la principal «amenaza» a la unidad de Estados Unidos es la «alta fertilidad» de los mexicanos, junto con su cultura y su lengua. Estos argumentos racistas y xenófobos, presentados como científicos, han contribuido a que se culpe a las adolescentes, en particular, y a los migrantes mexicanos en general de no asimilarse y de generar una carga económica para la sociedad. ${ }^{5}$ Una vez que Rosa dejó la escuela, empezó, al igual que su mamá, a trabajar limpiando casas.

Al tener un niño se me dificultó seguir estudiando. El orgullo de no agarrar ayudas de gobierno, porque hubiera podido seguir si yo me hubiera metido al welfaire, como madre soltera que yo era, pero no, no, no quise, porque me aferré, me subí en mi burro y yo dije: "yo quise tener a mi hija y ahora la cuido" (...). Yo entré a limpiar casas un tiempo. Y yo dije: "yo la saco adelante, así como metí el pie, ahora afronto yo sola". Y sí, fui y no me gustó, pero lo tuve que hacer para ganarme dinero. Porque mi mamá me decía: "no, no trabajes", pero yo dije: "¿por qué va a cargar ella completamente con todo si yo cometí el error? Yo cometí la falta, ahora a mí me toca afrontar las cosas" (entrevista, 2013).

Después de un tiempo, Rosa conoció a un joven con quien formó una pareja y tuvo tres hijos. Desde ese momento se dedicó de lleno al trabajo de crianza y a las múltiples tareas domésticas. Como ella explica, entrar a trabajar implicaría contratar a alguien para que cuidara a sus hijos, lo cual sería muy caro. La situación económica de esta joven familia no era fácil, ya que su única entrada de dinero era el salario de su esposo, quien se había especializado como instalador de alfombras, pero como no contaba con residencia legal tenía que trabajar para un contratista que se apropiaba de una buena parte de su ganancia. El estatus migratorio de Juan se ha convertido en un nuevo factor de exclusión que potencia las desigualdades de «raza» y de clase para Rosa y sus hijos. Por ejemplo, Juan no puede trabajar de manera independiente ya que no cuenta con número de seguro social, no puede emitir facturas, tampoco puede obtener un préstamo bancario, adquirir una vivienda propia, conseguir una licencia de conducir, etc. Además, toda la familia vive con estrés y miedo permanente a una eventual deportación.

5 Es el mismo tipo de prejuicios y estereotipos que suele utilizarse en contra de las mujeres afroamericanas. 


\section{Como explica Rosa:}

yo me siento como alguien que no soy de aquí [Estados Unidos], como si no fuera americana, porque siempre estoy con miedo, siempre estoy con el pendiente de que no lo vayan a parar. ¿Si me entiendes? Cuando salimos en carro veo un policía y siento el nervio (...). Imagínate, si lo deportan, ¿qué vamos hacer?, si es el único que trabaja (entrevista, 2013).

Rosa vive con un gran sentimiento de injusticia por no poder regularizar el estatus migratorio de su esposo, quien llegó al país a los doce años de edad, tiene tres hijos ciudadanos y paga impuestos. Al momento de la entrevista tenía la esperanza de que con la llegada de Obama podría regularizar su situación; lo cual no sucedió. Como señala Massey (2008), los mexicanos han sido sujetos de un proceso sistemático de formación racial para definirlos como parte de un grupo explotable y susceptible de exclusión. Existe una estrecha relación entre su racialización, su ilegalización y su explotación (De Genova, 2006), y esta situación no solo afecta a la generación indocumentada sino también a sus descendientes, quienes son vistos y tratados como extranjeros «ilegales».

Luego de varios años fuera de la escuela, Rosa retomó sus estudios y, al momento de la última entrevista, se preparaba para presentar el examen que le permitiría obtener un diploma equivalente al high school. Sus planes a futuro son regularizar la situación de su esposo y encontrar un trabajo en alguna de las compañías que tienen concesionado el transporte de la ciudad.

Desde las teorías de la asimilación segmentada (Portes y Zhou, 1993), la trayectoria de Rosa representa un caso de "asimilación descendente», en el que, en lugar de transitar hacia la clase media o por lo menos mejorar con respecto a sus padres, se ha orientado hacia los sectores más empobrecidos de la sociedad. Su paso a la adultez tampoco coincide con el modelo hegemónico de lo que debe ser una transición exitosa, ya que abandonó la escuela antes de terminar su educación básica, se embarazó muy joven, no ha logrado insertarse al mercado de trabajo ni formar un hogar independiente. No obstante, si consideramos aspectos como la responsabilidad y la autonomía, desde muy joven Rosa asumió un papel clave al interior de su familia, gracias a su manejo del inglés y a su comprensión del funcionamiento del sistema, además de ser un impulso muy significativo para su hermana menor.

Lo que me interesa destacar de esta trayectoria es cómo en la misma biografía se imbrican distintos ejes de desigualdad que sistemáticamente colocan a Rosa en una situación de desventaja. Su condición de clase y de «raza», además de su 
pertenencia a una familia migrante, la segregó a espacios residenciales pobres en los que habitan casi en exclusiva familias mexicanas o centroamericanas, lo que al mismo tiempo definió su asistencia a las peores escuelas de la ciudad. Su condición de género y clase determinó que, frente a un embarazo no esperado, tuviera que abandonar la escuela y asumir el sostén y la crianza de su bebé, lo cual derivó en su incorporación fugaz al mercado laboral como trabajadora doméstica, reproduciendo la trayectoria de su madre migrante. Posteriormente, también su condición de género la condujo a asumir la crianza de otros tres hijos; si bien ahora lo hizo con el sostén económico y afectivo de una pareja, esta responsabilidad no le ha permitido ingresar al mercado de trabajo y desarrollar una trayectoria profesional. En la actualidad, su vida y el futuro de su familia se ven afectados por las políticas de ilegalización dirigidas hacia los migrantes indocumentados, las que refuerzan y potencian las desigualdades de clase y de «raza», y reproducen el círculo de la pobreza a través de las generaciones.

\section{Llegar a la universidad, una carrera de obstáculos}

Al momento de la entrevista, Laura cursaba el primer año de la universidad. Sin embargo, a diferencia de otros hijos de migrantes, no sostenía un discurso celebratorio del esfuerzo personal ni se hacía ilusiones con el «sueño americano». Ella tenía una visión bastante pesimista de la sociedad y definía su trayectoria escolar como una «carrera de obstáculos». Dice que la principal barrera para entrar a la universidad es el SAT, un examen de admisión estandarizado que determina el ingreso y define a qué universidades ir. Si bien el examen pretende ser una prueba objetiva para medir, a través del «mérito académico», las habilidades y conocimientos adquiridos durante su formación, los jóvenes mexicanos y afroamericanos llegan al día del examen con tal acumulación de desventajas que no importa cuánto empeño pongan en su preparación, por lo general, su puntaje no alcanzará para ingresar a las universidades de prestigio. Como explica Laura:

ese examen es un obstáculo, un obstáculo que está ahí, porque, aunque aquí en Estados Unidos dicen mucho que "si tú quieres ir a una universidad puedes ir", este examen es como una pared grandota; "si tú quieres puedes", te dicen... Pero no es tan fácil, especialmente si quieres ir a las universidades buenas, como USLA, Harvard. Para todas esas escuelas buenas públicas, tienes que tener un buen exa- 
men, un buen score. El examen es de 2,400 puntos y muchos de nosotros, que salimos de escuelas hispanas aquí en estos barrios, agarramos posiblemente solo 1,000 o 900 puntos (...) Esos exámenes son muy difíciles, los únicos que los hacen bien son los americanos, o las gentes que tuvieron una educación muy buena. Y nosotros, cuando tomamos esos exámenes, pues... muchos ni la mitad de puntos agarramos... (entrevista, 2013)

La desigualdad de condiciones sobre la que se desarrolla la trayectoria escolar de cada estudiante es cubierta por un discurso meritocrático que postula que todos pueden alcanzar el éxito si se esfuerzan y se preparan bien. El SAT forma parte de una política educativa que reproduce la desigualdad social, pues provoca la exclusión de ciertos estudiantes al tiempo que consolida los privilegios de otros. Además, con este tipo de políticas educativas se refuerzan los estereotipos sociales sobre los supuestos «atributos» de los diferentes grupos, por ejemplo, la idea de que los «latinos» no son competentes para la escuela, en contraste con los «asiáticos» que han sido construidos como una «minoría modelo» en cuanto a trayectoria escolar y asimilación ascendente. Se refuerzan también los estereotipos sobre las carreras a las que pueden aspirar, el tipo de universidades a las que pueden asistir y la percepción de que hay universidades para «blancos» y otras para «latinos» y «negros», representaciones que los jóvenes interiorizan muy temprano y que impactan en sus aspiraciones educativas.

Muchos de nosotros, mexicanos, hispanos, vamos a universidades que no son como UCLA, que no son como Harvard (...). Casi las escuelas que están más llenas de hispanos son las California State University, que son como la que yo voy y que están llenas de hispanos, más que güeros. Las universidades que se llaman University of California, como UCLA, San Diego, esas escuelas se llenan más de güeros y asiáticos porque son mejores. Además, están las escuelas privadas como Harvard, USI, esas escuelas están más compuestas por güeros, o sea, por gente de dinero. Y hasta abajo están las Community College, porque muchos latinos vamos a las Community College que no requieren ni test (entrevista, 2013).

Esta clase de estereotipos permite que las profundas desigualdades sociales y económicas se encubran bajo un enfoque culturalista como el de Huntington (2004b). Bonilla Silva (2003) Ilama a esto un «racismo daltónico», el cual promueve como noción de sentido común que la desigualdad racial no tiene nada que ver con el racismo. 
Como les sucede a muchos estudiantes mexicoamericanos, Laura tuvo que tomar, en el primer año de universidad, uno de los llamados cursos de «remedio» que buscan nivelarlos con el resto de los estudiantes: "Como nosotros no tuvimos esa buena educación nos ponen en unas clases que se llaman de remedio y esas clases son las más pobladas por latinos y morenitos». Aunque Laura considera que para ella fueron cursos muy útiles, porque -en efecto- reconoce un rezago en su formación, el problema es que estos aumentan su carga de trabajo y alargan el tiempo de sus estudios, razón por la cual muchos jóvenes abandonan la universidad. Además, son cursos que los estigmatizan como los «malos estudiantes» y los culpan de que el sistema tenga que gastar recursos en darles una preparación que, se supone, ya deberían de tener.

Por el momento, la trayectoria de Laura parece seguir los dos proyectos normativos que buscan gestionar la inclusión de los jóvenes hijos de migrantes, pues concluyó la escuela básica e ingresó a la universidad, un logro que desde ambos modelos se considera determinante para completar con «éxito» las respectivas transiciones, aunque por sí mismo y en el contexto actual tampoco le asegura que logrará graduarse de la universidad, y menos aún que conseguirá el ascenso social. Lo que me interesa señalar es que, si bien llegó a la universidad, también la trayectoria de Laura ha estado marcada por un racismo estructural y sistémico, endémico a la estructura social estadounidense (Valdez y Golash-Boza, 2017), que la ha mantenido siempre en una situación de desventaja.

\section{José: lengua y racismo}

José Ríos nació en 1985 en San Isidro. Cuando tenía dos años sus padres emigraron a la ciudad de Los Ángeles, dejándolo bajo el cuidado de su tía. Dos años después volvieron por él y se lo llevaron a Estados Unidos. Su madre se ha dedicado a la limpieza de casas y su padre al trabajo en restaurantes; ambos regularizaron su situación migratoria en el contexto de la Amnistía de 1986. Al momento de la entrevista, José tenía 21 años, vivía con sus padres, trabajaba en una compañía dedicada a cuestiones de computación y, al mismo tiempo, estudiaba ingeniería en sistemas. José además era conocido en la comunidad de zapotecos de San Isidro en Los Ángeles por su pasión por la música y las danzas, 
ya que además de participar en las festividades de la comunidad, formaba parte de distintos grupos de baile y enseñaba las danzas tradicionales a los hijos de zapotecos de San Isidro nacidos en Estados Unidos. José pertenece a la llamada generación 1.5, es decir, aquellos que llegaron durante su infancia a Estados Unidos; así como se ha mantenido estrechamente vinculado a la comunidad zapoteca de San Isidro, también es visto como alguien «muy asimilado» a la cultura americana por su apariencia física, por su dominio del inglés, su nivel de estudios, su tipo de trabajo, entre otros aspectos.

En Estados Unidos el aprendizaje del inglés es uno de los principales indicadores de una «buena asimilación». En los discursos antimigrantes se ha construido a los mexicanos como personas que no quieren aprender inglés, aunque la evidencia científica muestre que los jóvenes de la segunda generación hablan inglés con soltura y que prefieren esta lengua para comunicarse entre ellos (Portes y Rumbaut, 2011; Telles y Ortiz, 2008).

Entre su generación José es uno de los raros casos de trilingüismo, pues habla inglés, español y zapoteco. Él considera que su lengua materna es el español, porque es la lengua que le hablaron de pequeño y la primera que aprendió; aunque el zapoteco lo ha escuchado desde chico en su hogar siempre le han prohibido hablarlo.

Mi madre siempre me decía: "no, no hables el zapoteco". Y yo le decía: "¿por qué mamá?", pues ella tenía miedo de que se me dificultara el inglés y el español, porque la mente de ellos era que yo triunfara en los Estados Unidos y que pudiera llegar a tener una buena vida (entrevista, 2006).

El que sus padres pensaran así era producto de su experiencia personal, en tanto hablantes de una lengua minorizada primero en el país de origen y luego en el de acogida. Es decir, tiene que ver con las políticas públicas que buscan consolidar la lengua nacional y acabar con las lenguas minoritarias. Como señala Rumbaut (2015:11), Estados Unidos puede ser definido como un «cementerio» de lenguas, debido a su capacidad histórica para extinguir las lenguas maternas de los inmigrantes en dos o tres generaciones.

José aprendió inglés durante su proceso de escolarización en Estados Unidos $y$, a decir de otros jóvenes mexicoamericanos, es uno de los pocos miembros de la comunidad zapoteca de San Isidro que «no tiene acento latino». El dominio 
del inglés es uno de los principales indicadores para «evaluar» el grado de «asimilación» de una persona migrante; es también, cuando se habla «con acento» o «incorrectamente», motivo de racismo y estigmatización. Como recuerda José:

desde que estaba chico mi madre me llevaba a su trabajo y yo veía que a mi mamá se le hacía difícil hablar el inglés, ella trataba de comunicarse con sus patrones, y yo veía cómo sufría al tratar de comunicarse (...). A veces yo escuchaba que los patrones le hacían burla a mi mamá, entonces es cuando dije: "yo tengo que aprenderlo" y eso es lo que me motivó, más que nada.

Yo, desde chico, siempre me empecé a tomar todo esto muy en serio. Muchos de los paisanos ahora dicen que soy muy callado, muy serio y sí es cierto, pero es que yo siempre he querido progresar, nunca me quería quedar abajo, más que nada por mis padres, porque yo veía que mis padres estaban sufriendo. Por ejemplo, si hay un pleito en el trabajo, mis padres no sabían cómo defenderse, entonces yo a veces tenía que interpretar lo que mi padre quería decir y, claro, como yo soy un niño chico, pues no me hacen caso (...), por eso yo siempre pensaba en progresar. Yo siempre tenía la idea de que "tengo que triunfar" (entrevista, 2006).

Desde muy joven, José asumió muchas responsabilidades y se convirtió en el intermediario entre su familia, las instituciones y el mundo «blanco» y angloparlante. Esta situación marcó su trayectoria y también su carácter. En el proceso de adaptación al país de acogida es frecuente que los jóvenes de la segunda generación tengan que asumir, en una etapa temprana, algunos de los roles paternos, ya que ellos aprenden el idioma más pronto y mejor que sus padres, así como el funcionamiento, los valores y las reglas de la nueva sociedad (Portes y Rumbaut, 2011). Lo anterior puede provocar un cambio de roles de autoridad entre padres e hijos que derive en la modificación de la dinámica familiar y, en el peor de los escenarios, podría llevar a la pérdida de la autoridad paterna y a que los jóvenes «se descarrilen» (Portes y Rumbaut, 2011). En el caso de José, el cambio de roles no mermó la autoridad paterna pero sí lo llevó a vivir bajo mucha presión para ayudar a sus padres, no decepcionarlos y cumplir con sus expectativas. 


\section{Una trayectoria escolar atípica}

Durante la primera etapa de su trayectoria escolar, José estudió en el mismo tipo de escuelas que Laura y Rosa. En este periodo lo que más lo marcó fue el racismo que tuvo que enfrentar al ser señalado como «indígena».

Yo me identifico como oaxaqueño y ahora lo digo con mucho orgullo, pero cuando estaba chico, no, porque me hacían burla. Cuando yo estaba en la escuela, me hacían mucha burla porque, según ellos, Oaxaca era un lugar muy pobre y todo eso (...). Yo no entendía por qué me burlaban a mí, pensaba que tal vez era más por mi color, porque hay mexicanos que tienen también piel clara y no es tanto lo que los burlan, cuando te burlan es cuando tienes un color café (entrevista, 2006).

Una vez concluida la primaria, y por consejo de sus profesores, José fue inscrito en una escuela de prestigio ubicada en un área donde solo viven «americanos blancos». Si bien para José y su familia esto fue visto como una gran oportunidad, también implicó muchos retos y dificultades que enfrentar a una corta edad.

Por mis calificaciones, los directores no me dejaron ir a la escuela aquí en Los Ángeles, así que me fui al valle. En mi escuela en ese tiempo casi no había latinos, yo era la única persona con color moreno; afroamericanos solo había como dos o tres por ciento. Ahí me pasaron cosas buenas y también he sufrido mucho por razones de que a veces no tenía el apoyo que necesitaba, pero de una manera o de otra trataba de conseguirlo (...). Es muy duro crecer con mucha presión, es muy duro crecer no teniendo nada, no ser como mis compañeros... Porque cuando yo empecé el high school, yo no tenía el respeto que tengo ahora porque, claro, todos tienen [dinero] y yo no tenía nada, en la escuela que yo iba todos tenían dinero y, claro, yo no (entrevista, 2006).

En estos espacios, los jóvenes mexicoamericanos se confrontan más directamente con las desigualdades desprendidas de su pertenencia a una clase social desfavorecida y a un grupo social racializado. Es decir, su lugar subordinado en la sociedad se hace más evidente frente a los privilegios de los otros estudiantes. Las desventajas de estos jóvenes no solo son económicas, sino que tienen que ver también con el acceso desigual a la información necesaria para tomar las mejores decisiones y para establecer las estrategias adecuadas para su éxito escolar. 
Además, en estos contextos, los jóvenes mexicoamericanos se enfrentan de forma permanente a los estereotipos negativos sobre los mexicanos y tienen que desplegar grandes esfuerzos para «probar» que su realidad no tiene correspondencia con el prejuicio. Algo que no es fácil porque, como señala Bonilla-Silva (1997:476), los estereotipos raciales se cristalizan en el nivel ideológico del sistema social y estas imágenes, en última instancia, indican y justifican la posición del grupo estereotipado en una sociedad, por lo que para los grupos dominantes es importante mantenerlos. Cuando los jóvenes mexicoamericanos estudian en escuelas con alumnado «blanco», de clase alta, quedan más expuestos a experiencias de estereotipación y racismo, y corren mayor riesgo de abandonar la escuela pues «las desventajas que se asocian con su procedencia étnica se vuelven altamente visibles, lo que les hace estar expuestos a una mayor discriminación» (Portes y Hao, 2005:35).

\section{La entrada al mercado laboral}

Mientras estudiaba el high school, José tuvo que trabajar para solventar sus gastos: «no quería molestar a mis padres, no los quería hacer sufrir porque yo sé que durante estos años ellos han sufrido». Su primer trabajo fue en un restaurante de comida rápida, porque solo ahí aceptaban menores de edad y José todavía no cumplía los 16 años. Sin embargo, solo permaneció una semana, ya que un vecino lo ayudó a incorporarse a una empresa de servicios de informática. Unos años atrás, los padres de José hicieron grandes esfuerzos para mudarse a un barrio en el cual, si bien había mucha población latina, habitaban también familias de otros orígenes -por ejemplo asiáticos-y de distintas clases sociales. Ahí José conoció a Tom, un ingeniero americano, a quien, a pesar de su estatus, le gustaba vivir en el barrio. Tom fue pieza clave en la trayectoria de José:

Entonces yo quería un trabajo y le comenté a mi vecino que era ingeniero en computación: "yo quiero trabajo, yo quiero trabajo". Yo iba todas las noches a aprender algo ahí [a su casa] porque a mí me encantaba todo lo que era la computación y a él le gustaba que fuera, porque así entretenía a su hija, porque tenía una hija pequeña (...). Y cuando por fin tuve trabajo en el KFC cada vez que yo salía iba 
con mi vecino y le reclamaba: "¿sabes qué? no me gusta mi trabajo, no me gusta mi trabajo". Al sexto día Tom me dijo: "tal vez en mi trabajo puedes hacer algo, tú ya sabes hacer fotografías por Internet, ya sabes manejar máquinas, ve a este lugar de mi parte y te van a entrevistar" (entrevista, 2006).

José se presentó a la entrevista. "Y por suerte ese día algo pasó: cuando llegué allá, las computadoras se apagaron y el ingeniero estaba en Santa Mónica, por lo que tuve la oportunidad de enseñarle a ese mánager lo que podía hacer». Desde entonces, José trabaja para esa empresa y actualmente ocupa un puesto como supervisor, es el único latino en la compañía y el más joven. Si bien José considera que esto le ha permitido adquirir cierto «respeto», una mejor situación económica y estatus, el racismo es, aún, parte de su cotidianidad:

Ahorita yo soy mánager de la compañía y pues han habido situaciones en que el cliente se me queda mirando y me dice: "no entendiste ¿verdad?, dije que quiero hablar con el mánager", y le digo: "sí, discúlpeme, yo soy el mánager"; y se me queda viendo y me dice "¿tú eres el mánager?"; "sí, soy el mánager ¿en qué le puedo ayudar?". Y se me queda viendo por razones de que ¿por qué un latino es mánager? En cambio, es común de que si ven a Kevin Miller, que es otro de los supervisores como yo, nadie dude que es el supervisor (entrevista, 2006).

Además, al interior de su compañía, José es testigo de prácticas racistas que no son permitidas por la ley pero que se reproducen todos los días muros adentro:

El racismo existe, existe. En mi compañía un buen ejemplo es que ellos no aceptan a ningún latino, cada vez que hay un CV de cualquier empleado que sea latino lo tiran a la basura. Y yo lo veo porque tenemos juntas todos los martes. Y a veces veo que los CV que manda la gente son buenos, que son de graduados de colegios como USE, UCLA, o sea universidades grandes, pero como dicen "Hernández", "López", "Castañeda", pues los ignoran (...). "No vamos a agarrar a esa persona porque qué tal que no tiene buena educación", eso es lo que ellos comentan, y eso que yo estoy en la mesa. Yo sé que eso que hacen es ilegal, pero pues no puedo decir mucho porque como son siete contra uno, pues ni modo, no puedo decir nada (entrevista, 2006).

Al momento de la entrevista José quería cambiar de carrera. Su nuevo plan era estudiar ingeniería biológica porque le veía un mejor futuro y le resultaba más interesante que la informática. Sin embargo, temía que sus padres no estuvieran de acuerdo por miedo a que al final no concluyera ninguna carrera. 
José era visto al interior de la comunidad zapoteca de San Isidro como «un ejemplo» y como "una prueba» de que es posible el «sueño americano» y de que este depende del esfuerzo personal:

hay mucha presión, especialmente ahorita, porque varios de mis primos como que no salieron del colegio, ya no quisieron ir a la universidad; varios de ellos nada más han ido un año, otros de ellos solo han ido dos años, y a varios de ellos no les ha gustado para nada (...). Para mí es mucha presión, porque si termino mal mis padres y mi familia van a decir: "ahí salió otro perdedor" y yo no quiero que mis padres digan eso. Por eso hay mucha presión en mí. Y luego mi familia también, no quiero que mis primos digan: "mi primo le echó ganas, pero de repente también bajó, ¿qué pasó con él?". Entonces por eso hay mucha presión (entrevista, 2006).

La trayectoria de José ilustra lo que desde el modelo normativo de la transición a la adultez sería una «transición exitosa», algo muy difícil de alcanzar en el contexto en el que creció. José logró tener acceso a escuelas que, por situarse en barrios «blancos», son espacios reservados casi exclusivamente a estudiantes blancos y anglófonos, y también pudo ingresar a la universidad; aunque al momento de la entrevista todavía no se había graduado todo parecía indicar que tenía amplias posibilidades de hacerlo. Además, consiguió insertarse muy joven en el mercado laboral y ocupar un puesto que personas jóvenes y mexicanas raras veces pueden obtener. En el modelo de Portes y Zhou (1993), la trayectoria de José podría definirse como de «asimilación ascendente» con «aculturación selectiva», es decir, ha logrado ascender socialmente -lo que él define como «obtener respeto»-y participar del mundo de la clase media blanca, al tiempo que mantiene su lengua materna y fuertes lazos con la comunidad de San Isidro. Este tipo de trayectorias han sido tomadas por algunos teóricos de la asimilación (Alba y Nee, 2003) como «prueba» de que, pese a todos sus problemas, la sociedad estadounidense finalmente es una sociedad incluyente. Lo cual ha recibido fuertes críticas porque provoca que se invisibilice la persistencia de una estructura social racializada que organiza las relaciones sociales y produce sufrimiento y grandes desventajas en los sujetos racializados. Un aspecto significativo de esta trayectoria es que nos permite ver la forma que toma el racismo cuando los jóvenes se 
desenvuelven lejos del barrio, en contextos de mayor interacción con el mundo «blanco». Además, nos permite observar cómo, en su manera de percibir el mundo coexiste la ideología del mérito, del esfuerzo personal y del «sueño americano», con un discurso crítico sobre el racismo; sin embargo, también es posible percibir las dificultades de los entrevistados para hacer conexiones directas entre el racismo estructural y sus respectivas experiencias.

\section{Reflexiones finales}

En este artículo se analizó, a partir de un enfoque biográfico, cómo tres jóvenes mexicoamericanos -dos de ellas hermanas-, hijos de migrantes zapotecos de San Isidro establecidos en Los Ángeles, California, experimentan las desigualdades que se derivan de las relaciones de género, clase y particularmente «raza», y de qué forma estas impactan sus trayectorias de vida. Estos jóvenes deben hacer frente a dos proyectos normativos en los que se expresan las expectativas de la sociedad adulta, los cuales intentan regular su inclusión social a partir de instituciones como la escuela y la familia, y diferentes dispositivos como las políticas migratorias, sociales y educativas. Además, son proyectos que producen potentes representaciones sociales sobre los roles esperados -y también los considerados inaceptables- de los jóvenes y de los migrantes. Dada la fuerza de estos discursos y su capacidad para producir subjetividades, no pocas veces los hijos de migrantes hacen suyos estos proyectos y estas representaciones. Revisar las trayectorias de los hijos de migrantes zapotecos a la luz de estos proyectos normativos permitió alumbrar las tensiones y contradicciones que enfrentan los hijos de migrantes al tratar de cumplir con ellos en un contexto en el que todo está estructurado de manera que su inclusión social sea improbable o se realice en términos muy precarios, es decir, de forma débil, inestable y fugaz.

Como han señalado Valdez y Golash-Boza (2017:6), en Estados Unidos todas las relaciones y jerarquías de género, clase, «raza», etnicidad -y también edadocurren dentro de una "estructura social racializada» que está arraigada dentro de un sistema de supremacía blanca, en el cual el grupo dominante clasifica a las personas en grupos raciales basándose en características fenotípicas atribuidas, independientemente de la autoidentificación (Valdez y Golash-Boza, 2017:4-5). 
La clasificación racial determina la posición de cada grupo en la jerarquía racial estadounidense y confiere, más o menos, privilegios u opresión, por lo que es estructuralmente importante para todos los grupos (Valdez y Golash-Boza: 2017:2).

Como lo hace notar Ortiz (2017:2), el marco racial ha sido ampliamente utilizado para el estudio de los «negros», pero rara vez se ha usado para el estudio de los «blancos» o de los considerados «no negros, ni blancos», como es el caso de los mexicoamericanos. Por lo regular ellos han sido estudiados desde las teorías de la asimilación, bajo un enfoque centrado en la etnicidad en el que son vistos como una «minoría étnica» producto de la inmigración (Telles y Ortiz, 2008; Ortiz y Telles, 2012). La hegemonía de las teorías de la asimilación, así como de la ideología asimilacionista ha provocado que se minimice e invisibilice el papel preponderante que juegan las relaciones y jerarquías de «raza» en los logros educativos y económicos de los mexicoamericanos, en el lugar que ocupan en el mercado de trabajo y, en general, en todos los aspectos de su vida (Telles y Ortiz, 2008; Ortiz y Telles, 2012).

Este artículo ha intentado contribuir a esclarecer cómo esta estructura racializada impacta de manera concreta en la vida de los hijos de migrantes mexicanos de origen indígena que nacieron en Los Ángeles o que llegaron muy jóvenes a esa ciudad; para ello se presentaron las trayectorias biográficas de tres jóvenes de origen zapoteco, las cuales nos permiten observar cómo se producen las desigualdades derivadas de las relaciones de «raza», clase y género, y cómo estas estructuran su experiencia en el día a día.

Por ejemplo, pudimos observar cómo su transición a la adultez y su proceso de asimilación están marcados por una experiencia de segregación racial y de clase, ya que las escuelas a las que asisten están pobladas de forma exclusiva por estudiantes pobres o de clase trabajadora, de origen latino y afroamericano; estas escuelas, catalogadas como «las peores de la ciudad», deben funcionar con muchos menos recursos que las escuelas que concentran al alumnado blanco y de clases acomodadas. La segregación por «raza» y clase está tan naturalizada que, en las representaciones sociales que estos jóvenes tienen de la ciudad, todo está separado racialmente, por eso es común que hablen de «escuelas de blancos», «escuelas de latinos», «barrios de blancos», «barrios de latinos», «tiendas para güeros», «tiendas para latinos», etc. A pesar de estar naturalizada, existe plena conciencia de que es un orden injusto, aunque muy difícil de cambiar. 
También observamos cómo en las experiencias de estos jóvenes se imbrican dos estructuras raciales en las que ocupan los peldaños más bajos: la de la sociedad de origen, expresada en las relaciones cara a cara que tienen lugar en la escuela, por medio de la burla, el maltrato y la discriminación, al ser estereotipados como indígenas o como "oaxacos»; y la estructura de la sociedad de acogida, que se expresa bajo la forma de un racismo estructural fincado en un sistema de supremacía blanca que constriñe fuertemente sus oportunidades de vida. Los jóvenes mexicoamericanos que, como José, se desenvuelven en ambientes «blancos» estarán expuestos con más fuerza al racismo que se expresa en las interacciones sociales cara a cara y sufrirán de manera directa los estereotipos.

El género también provoca grandes desventajas en las biografías de algunas mujeres, en particular cuando existe un embarazo temprano, situación que conlleva el abandono escolar y dificulta la superación de una situación de pobreza; condiciones específicas a las que no se enfrenta necesariamente un hombre.

Por último, también pudimos constatar cómo los jóvenes mexicoamericanos, si bien son ciudadanos, sufren las consecuencias de las políticas migratorias ya que son percibidos, estereotipados y tratados como "extranjeros» y como «ilegales» solamente por la apariencia física percibida. Además, para aquellos que como Rosa están casados con un migrante irregularizado o tienen un familiar cercano en esta situación, estas políticas producirán precariedad y mantendrán a la familia en una situación de gran vulnerabilidad.

Queda para futuros artículos mostrar el papel que juegan tanto la agencia de los sujetos como su pertenencia comunitaria al pueblo de origen para compensar o superar las desigualdades derivadas del racismo estructural.

\section{Agradecimientos}

Este artículo se escribió con el apoyo de una beca del CONACyT (2018-2019) para una estancia sabática en el extranjero. 


\section{Bibliografía citada}

Alba, Richard y Victor Nee. (1997). Rethinking Assimilation Theory for a New Era of Immigration, International Migration Review, 31(4), pp. 826-874.

Alba, Richard y Victor Nee. (2003). Remaking the American Mainstream: Assimilation and Contemporary Immigration. Cambridge: Harvard University Press.

Alpizar, Lydia y Marina Bernal. (2003). La construcción social de las juventudes, Última Década, 19, pp. 1-20.

Bertaux, Daniel. (1999). El enfoque biográfico, su validez metodológica, sus potencialidades, Proposiciones, 29. Disponible en: http://www.sitiosur.cl/detalle-de-la-publicacion/?el-enfoque-biografico-su-validez-metodologica-sus-potencialidades (consulta: $15 / 01 / 2020)$.

Bertaux, Daniel. (2005). L'Enquête et ses méthodes: Le récit de vie. París: Armand Colin.

Bonilla-Silva, Eduardo. (1997). Rethinking Racism: Toward a Structural Interpretation, American Sociological Review, 62(3), pp. 465-480.

Bonilla-Silva, Eduardo. (2003). Racism without Racists: Color-blind Racism and the Persistence of Racial Inequality in the United States. Nueva York: Rowman and Littlefield.

De Genova, Nicholas. (2006). Racial Transformations: Latinos and Asians Remaking the United States. Durham: Duke University Press.

Flores, Antonio. (2017). How the U.S. Hispanic population is changing. Recuperado de: https://www.pewresearch.org/fact-tank/2017/09/18/how-the-u-s-hispanic-population-is-changing/ (consulta: 15/01/2020).

Gordon, Milton. (1964). Assimilation in American Life: The Role of Race, Religion, and National Origin. Nueva York: Oxford University Press.

Huntington, Samuel. (2004a). El desafío hispano, Letras Libres, 64. Recuperado de: https:// www.letraslibres.com/mexico/el-desafio-hispano (consulta: 15/01/2020).

Huntington, Samuel. (2004b). ¿Quiénes somos? Los desafíos a la identidad nacional estadounidense. México: Paidós.

Massey, Douglas. (2008). La racialización de los mexicanos en Estados Unidos: estratificación racial en la teoría y en la práctica, Migración y Desarrollo, 10, pp. 65-95.

Montejano, David. (1987). Anglos and Mexicans in the Making of Texas: 1836-1986. Austin: University of Texas Press.

Mora, Minor y Orlandina de Oliveira. (2009). Los jóvenes en el inicio de la vida adulta: trayectorias, transiciones y subjetividades, Estudios Sociológicos, 27(79), pp. 267-289.

Ngai, Mae. (2004). Impossible Subjects: Illegal Aliens and the Making of Modern America. Princeton: Princeton UP.

Ortiz, Vilma y Edward Telles. (2012). Racial Identity and Racial Treatment of Mexican Americans, Race and Social Problems, 4(1), doi: 10.1007/s12552-012-9064-8

Ortiz, Vilma. (2017). Towards unifying racial and ethnic paradigms, Ethnic and Racial Studies, 40(13), pp. 2240-2248.

Portes, Alejandro y Lingxin Hao. (2005). La educación de los hijos de inmigrantes: efectos contextuales sobre los logros educativos de la segunda generación, Migraciones, 17, pp. 7-44. 
Portes, Alejandro y Min Zhou. (1993). The New Second Generation: Segmented Assimilation and Its Variants, The Annals of the American Academy of Political and Social Science, 530, pp. 74-96. Recuperado de: http://www.jstor.org/stable/1047678 (15/01/20).

Portes, Alejandro y Rubén Rumbaut. (2005). The Second Generation and the Children of Immigrants Longitudinal Study, Ethnic and Racial Studies, 28(6), pp. 983-99, doi:10.1080/01419870500224109

Portes, Alejandro. y Rubén Rumbaut. (2011). Legados. La historia de la segunda generación inmigrante. México: Centro de Estudios Migratorios del Instituto Nacional de Migración/Porrúa.

Portes, Alejandro. (2006). La nueva nación latina: inmigración y la población hispana de los Estados Unidos, REIS, 116(6), pp. 55-96.

Portes, Alejandro, Patricia Fernández-Kelly y William Haller. (2006). La asimilación segmentada sobre el terreno: la nueva segunda generación al inicio de la vida adulta, Migraciones, 19, pp. 7-58.

Rumbaut, Rubén. (2015). Assimilation of Immigrants. En James Wright (ed.). International Encyclopedia of the Social \& Behavioral Sciences, vol. 2. Oxford: Elsevier.

Saravi, Gonzalo. (2006). Biografías de exclusión: desventajas y juventud en Argentina, Perfiles Latinoamericanos, 28, pp. 83-116.

Saravi, Gonzalo. (2009). Desigualdad en las experiencias y sentidos de la transición escuela-trabajo, Papeles de Población, 15(59), pp. 83-118.

Suárez-Orozco, Carola y Marcelo Suárez-Orozco. (2001). Children of immigration. Cambridge: Harvard University Press.

Telles, Edward y Vilma Ortiz. (2011). Racialization and Mexican American Incorporation: A Reply to Lawrence Bobo and José Itzigsohn, Du Bois Review: Social Science Research on Race, 8(2), pp. 506-510.

Valdez, Zulema y Tanya Golash-Boza. (2017). U.S. racial and ethnic relations in the twenty-first century, Ethnic and Racial Studies, 40(13), pp. 2181-2209, doi: 10.1080/01419870.2016.1262052

Yankelevich, Pablo. (coord.). (2015). Inmigración y racismo. Contribuciones a la historia de los extranjeros en México. México: El Colegio de México.

\section{Cómo citar este artículo:}

Aquino Moreschi, Alejandra. (2020). «Conmigo, el sueño americano no se cumplió» Desigualdades de raza y clase en las trayectorias biográficas de hijos de migrantes zapotecos en Estados Unidos. Revista Pueblos y fronteras digital. 15, pp. 1-26, doi: 10.22201/cimsur.18704115e.2020.v15.462 